\title{
EXERCÍCIOS DE INTERPRETAÇÃO DO ART. 2 DA CONSTITUIÇÃO ITALIANA
}

\author{
RICCARDO GUASTINI*
}

\begin{abstract}
RESUMO: O texto analisa problemas interpretativos suscitados pelo art. $2^{\circ}$ da Constituição italiana, mormente no que tange à prescrição "A República reconhece $\mathrm{e}$ garante os direitos invioláveis do homem (...)”. São discutidas as questões do reconhecimento ou positivação; dos direitos aos quais a norma se refere e do sentido da inviolabilidade afirmada, concluindo-se que tais problemas interpretativos decor-rem não da ambigüidade lingüística do dispositivo, mas das conflitantes posições filosóficojurídicas ou -políticas conflitantes dos juristas.
\end{abstract}

PALAVRAS-CHAVE: Direitos Fundamentais. Interpretação. Constituição Italiana.

ABSTRACT: The text analyses interpretative problems raised by art. 2 of the Italian Constitution, especially concerning the prescription "The Republic recognizes and guarantees the inalienable rights of men (...)". It discusses the matters of the acknowledgment or positivation; of the rights to which the norm refers itself and of the meaning of the prescribed inalienability, concluding that such interpretative problems result not from the prescription's linguistic ambiguity but from the legal experts' conflicting legal-philosophical and -political beliefs instead.

KEYWORDS: Fundamental Rights. Interpretation. Italian Constitution.

SUMÁRIO: 1. Norma Imperativa ou Constitutiva?; 2. Reconhecimento ou Criação de Direitos?; 3. Quais Direitos?; 4. "Invioláveis”: em que sentido?; 5. Sem Conclusão.

SUMMARY: 1. Imperative or Constitutive Norm?; 2. Rights Recognition or Rights Creation?; 3. Which Rights?; 4. "Inalienable": in which sense?; 5. Void of Conclusion.

Proponho-me a ilustrar alguns problemas interpretativos levantados pelo incipit do art. 2 da Constituição italiana ${ }^{\mathrm{NT}}$ : «A República reconhece e garante os direitos invioláveis do homem [...]».

\section{NORMA IMPERATIVA OU CONSTITUTIVA?}

«A República reconhece e garante...»: em que sentido? É notório que, nos textos normativos, o uso dos verbos no presente do indicativo é pragmaticamente ambíguo:

Artigo recebido em 4.08.2009 e aprovado para publicação pelo Conselho Editorial em 10.12.2009.

* Professor do Departamento de Cultura Jurídica “Giovanni Tarello”, Universidade de Gênova.

Traduzido por Henrique Moreira Leites.

NT As referências a disposições da Constituição e legislação, ao longo do texto, referem-se aos textos normativos italianos. 
por vezes exprime uma norma imperativa, ou seja, um comando (a República deve reconhecer e garantir...); outras vezes exprime uma norma permissiva (a República pode reconhecer e garantir...); outras vezes, ainda, uma norma constitutiva (os direitos em questão são aqui e agora, ipso iure, reconhecidos e garantidos pela República) ${ }^{1}$. $\mathrm{O}$ art. 2 da Constituição admite, portanto, sob este particular aspecto, não menos do que três interpretações distintas.

(i) Em verdade, a segunda interpretação - a disposição exprime uma norma permissiva - não parece plausível, e, de fato, nunca ninguém sonhou propô-la.

Não se vê qual poderia ser a razão de uma norma que permitisse aos órgãos do Estado (“a República”, ou seja, os poderes públicos) reconhecer e garantir certos direitos que, contextualmente, são qualificados como "invioláveis”. Uma norma semelhante seria obviamente redundante ${ }^{2}$. Um direito que se entenda inviolável não pode não ser igualmente reconhecido e garantido: é impensável que não seja permitido aos poderes públicos reconhecer e garantir um direito que se entende inviolável ${ }^{3}$ ?

(ii) A terceira interpretação - a disposição exprime uma norma constitutiva parece ser quase pacífica na doutrina ${ }^{4}$. No meu entender, todavia, esta interpretação nunca foi convenientemente argumentada (com efeito, nunca foi argumentada de modo algum). Provavelmente, a idéia subjacente é, a grosso modo, a seguinte: declarar um direito "inviolável” não é algo diferente de conferi-lo; e conferir um direito não é outra coisa senão reconhecê-lo e garanti-lo.

Em verdade, este modo de ver parece um tanto frágil. Pode-se convir que declarar inviolável um direito e reconhecê-lo (conferi-lo, atribuí-lo) são a mesma coisa ${ }^{5}$. Contudo, restam, ao menos, dois problemas, dos quais não se vê a solução.

Em primeiro lugar, faz sentido conferir um direito “inominado” (ou uma pluralidade de direitos “inominados”)? Parece, exatamente, que não. Qual seria, em tal caso, o conteúdo do direito conferido?

Em segundo lugar, reconhecer um direito e garanti-lo são, evidentemente, coisas muito diversas. Para "reconhecer” um direito é (necessária e) suficiente uma norma que solenemente o proclame ou expressamente o confira. Para "garanti-lo" é necessária ao menos uma norma ulterior, mais provavelmente um complexo de normas ulteriores: uma ou mais normas que instituam um órgão e/ou um procedimento idôneos a proteger

\footnotetext{
${ }^{1}$ É constitutiva, nesse sentido, uma norma que não prescreve a quem quer que seja que faça algo (de modo que é desprovida de destinatários, não pode ser violada nem, de resto, obedecida), mas produz diretamente um efeito jurídico. Esse peculiar conceito de norma constitutiva foi elaborado, sobretudo, por G. Carcaterra, de quem se vejam: Le norme costitutive, ed. provvisoria, Milano, 1974; La forza costitutiva delle norme, Roma, 1979; Corso di filosofia del diritto, Roma, 1996.

${ }^{2}$ Falando de modo geral, os juristas são avessos a interpretações que tornariam redundante o conteúdo normativo das fontes. Cf., G. Lazzaro, Entropia della legge, Torino, 1985, 31 ss.

${ }^{3}$ Falando de modo geral, uma norma permissiva não pode senão cumprir a uma ou a outra das duas seguintes funções: ab-rogar ou derrogar uma proibição preexistente, ou seja, prevenir (tornando-a inválida) uma proibição futura. Cf., F. Poggi, Norme permissive, Torino, 2005.

${ }^{4}$ Cf., por exemplo, A. Baldassarre, "Diritti inviolabili”, in Enciclopedia giuridica [Treccani], vol. XI, Roma, Istituto dell’Enciclopedia, 1989, 10.

${ }^{5}$ A. Pace, Problematica delle libertà costituzionali. Parte generale, III ed., Padova, 2003, 177 s.
} 
o direito em questão, ou seja, a impedir a violação ex ante e/ou a remediar a sua violação ex post ${ }^{6}$. No constitucionalismo clássico, por exemplo, é pacífico que a “declaração dos direitos” é pouco valorizada se não for acompanha pela "separação dos poderes”: se os poderes não são separados, os direitos - ainda que declarados não estão garantidos ${ }^{7}$.

(iii) A primeira interpretação - a disposição exprime uma norma imperativa parece mais sólida.

É preciso notar que a disposição de que se discute não é formulada, como se convém, por uma norma constitutiva (algo como: “Os direitos invioláveis são reconhecidos e garantidos", "A presente constituição reconhece e garante os direitos invioláveis"). O sujeito, a que são referidas as ações de "reconhecer” e "garantir", não é a Constituição, mas a República; de modo que não se pode dizer que a própria Constituição diretamente "reconheça" e "garanta" os direitos em questão. Parece, antes, que a Constituição ordene (ou recomende) o reconhecimento à República. Diversamente, a menção da "República", a que a norma em evidência se dirige, não teria razão de ser.

Novamente, pode-se também questionar se tem sentido reconhecer constitutivamente já não um direito determinado (a liberdade pessoal, a liberdade de manifestação do pensamento, etc.), como fazem - com fórmulas inequívocas ${ }^{8}$ outras numerosas disposições constitucionais, mas direitos menos especificados. A resposta é não, ao menos que se entenda que uma lista de direitos invioláveis escrita, talvez, na natureza das coisas, ou na reta razão ${ }^{9}$ - preexista ao texto constitucional, seja pressuposta pela Constituição, e seja suscetível de conhecimento. Mas este ponto levanta um outro problema de interpretação, que discutiremos adiante.

Sobretudo, é necessário insistir que, se o formal reconhecimento ou atribuição de um direito pode ser realizado mediante uma norma constitutiva, uma norma semelhante não é, porém, idônea a assegurar a garantia. Parece óbvio que a disposição em questão, admitido também que reconheça certos direitos (o que, como se disse, é ao menos discutível), certamente não é suficiente a garanti-los. Antes, ela ordena (ou recomenda) à República a garanti-los mediante atos oportunos (sobretudo legislativos $)^{10}$.

Desse ponto de vista, o art. 2 da Constituição se inscreve plenamente na classe das disposições chamadas "programáticas”: disposições, isto é, dirigidas ao legislador (e, de modo geral, aos poderes públicos, aí incluídos - porque não? - os juízes), que prescrevem a realização de um certo programa de política do Direito: no caso em espécie, a proteção dos direitos invioláveis.

${ }^{6}$ A. Pace, Problematica delle libertà costituzionali, cit., 79.

${ }^{7}$ Recorde-se o art. 16 da Déclaration des droits de l'homme et du citoyen, 1789: «Uma sociedade em que não seja assegurada a garantia dos direitos e não seja determinada a separação dos poderes não tem uma constituição».

${ }^{8}$ Inequívocas, no sentido que têm, evidentemente, valor constitutivo: «A liberdade pessoal é inviolável» (art. 13, alínea I), «Todos têm direito de manifestar livremente o próprio pensamento» (art. 21, alínea I), etc.

${ }^{9}$ Eventualmente, na "reta razão", que se manifesta na tradição do constitucionalismo moderno.

${ }^{10}$ A. Pace, Problematica delle libertà costituzionali, cit., $16 \mathrm{~s}$. 
O problema até aqui discutido não parece agora $^{11}$ ter grande importância do ponto de vista estritamente jurídico. Todavia, reveste uma certa importância do ponto de vista político. Se entendemos que certos direitos (mas quais?) sejam, sem dúvida, reconhecidos e garantidos pela Constituição, então tudo o que se requer ao legislador e aos outros poderes públicos é de não violá-los. Se, pelo contrário, entendemos que a Constituição tenha traçado um programa de política do Direito, então o que se requer ao legislador e aos outros poderes públicos é precisamente realizá-lo. De outra parte, a solução deste primeiro problema está fatalmente destinada a orientar a solução de outros problemas interpretativos levantados pelo art. 2 da Constituição.

\section{RECONHECIMENTO OU CRIAÇÃO DE DIREITOS?}

O uso do verbo "reconhecer” («A República reconhece... os direitos invioláveis do homem») levanta um problema ulterior delicado. Literalmente, um "reconhecimento" - como uma “declaração" - é um ato cognitivo, que tem por objeto um estado de coisas, uma entidade, um evento, um fenômeno, preexistente. “A idéia de um reconhecimento pressupõe [...] a preexistência dos direitos, assim reconhecidos, respectivamente ao ordenamento estatal reconhecedor»" ${ }^{12}$. Pois bem: devemos, ou não, levar a sério a expressão - uma voz do verbo "reconhecer" - usada pelos constituintes ${ }^{13}$ ?

Se a levamos a sério, devemos concluir que a Constituição remete a um catálogo - aliás indeterminado - de direitos preexistentes: direitos que a Constituição não “cria” ex novo, mas, exatamente, limita-se a "reconhecer” ou declarar ${ }^{14}$.

Se, ao contrário, não a levamos a sério - se pensamos que se trata só de um modo de exprimir-se enfático e pouco meditado - devemos concluir que a Constituição remete simplesmente a si mesma, ou seja, ao catálogo de direitos expressamente mencionados nas disposições sucessivas.

A questão envolve, fatalmente, as convicções filosófico-jurídicas dos intérpretes: jusnaturalismo ou positivismo jurídico ${ }^{15}$ ?

\footnotetext{
${ }^{11}$ No período intercorrente entre a entrada em vigor da Constituição (1948) e a concreta ativação da Corte constitucional (1956), a Corte de cassação costumava distinguir dois tipos de normas constitucionais: normas “preceptivas” e normas "programáticas”, sustentando a não idoneidade destas últimas a ab-rogar, por incompatibilidade, leis antecedentes (cf., por exemplo, Cass. pen., Sessões unidas, 7 de fevereiro de 1948, in Foro italiano, 1948, II, 57). A Corte constitucional, desde a sua primeira sentença (Corte constitucional 1/1956), estabeleceu: (a) que a distinção entre normas preceptivas e programáticas pode ser relevante para decidir futura ab-rogação de leis antecedentes à Constituição; (b) que, porém, aquela mesma distinção não é decisiva nos juízos de legitimidade constitucional, já que a ilegitimidade constitucional de uma lei pode decorrer, indiferentemente, seja do seu contraste com uma norma preceptiva, seja do seu contraste com uma norma programática. Tal orientação jurisprudencial foi propiciada pela obra de V. Crisafulli, La costituzione e le sue disposizioni di principio, Milano, 1952.

${ }^{12}$ L. Paladin, Diritto costituzionale, Padova, 1995, 557.

${ }^{13}$ Cf., P. F. Grossi, I diritti di libertà ad uso di lezioni, II ed., Torino, 1991, 95 s.

14 «Ponto comum [...] nas posições firmadas no debate jurídico é dado pela afirmação [...] da precedência ou anterioridade de alguns direitos respectivamente ao ordenamento jurídico»: assim, E. Rossi, in R. Bifulco, A. Celotto, M. Olivetti (eds.), Commentario alla Costituzione, Torino, 2006, vol. I, sub art. 2, 43.

${ }^{15}$ L. Mengoni, "Fondata sul lavoro: la Repubblica tra diritti inviolabili dell'uomo e doveri inderogabili di solidarietà”, in M. Napoli (ed.), Costituzione, lavoro, pluralismo sociale, Milano, 1998, 3 ss.
} 
(1) Os partidários do jusnaturalismo entendem que existam "in natura” direitos (subjetivos), antecedentes a qualquer disciplina positiva e independentes dessa: direitos, portanto, que a Constituição se limita a reconhecer (nem poderia fazer diferentemente, no sentido de que poderia talvez desconhecê-los, mas certamente não “criá-los") ${ }^{16}$. Deste ponto de vista - poder-se-ia dizer - o texto constitucional, paradoxalmente, é um texto não genuinamente prescritivo (conferir direitos, é, de fato, um modo de prescrever), mas descritivo ou recognitivo dos direitos preexistentes ${ }^{17}$.

(2) Pelo contrário, os partidários do positivismo jurídico entendem que não existem in natura direitos (subjetivos) preexistentes ao ordenamento positivo, e que, portanto, os direitos em questão já não sejam - literalmente - reconhecidos, mas criados e conferidos aos cidadãos originariamente pela Constituição ${ }^{18}$. As formulações meramente "recognitivas" encontradas nessa, como em muitos outros documentos constitucionais $^{19}$, obviamente não provam que verdadeiramente existam direitos subjetivos naturais: quando muito, testemunham que essa era a ideologia dos constituintes ${ }^{20}$.

Todavia, as diferentes opções filosófico-jurídicas ${ }^{21}$ têm consequências dogmáticas

${ }^{16}$ C. Mortati, Istituzioni di diritto pubblico, VIII ed., Padova, 1969, vol. I, 146: «Falou-se de "reconhecimento" de direitos invioláveis, querendo-se significar que o Estado não os cria mas os encontra enraizados na consciência social». Cf., também, M. Mazziotti di Celso, Il diritto al lavoro, Milano, 1956, 88 ss.

${ }^{17}$ «Usando o verbo "reconhecer”, a Constituição quer evidentemente entender que não é a República que atribui os direitos invioláveis, mas que estes já existem independentemente de qualquer atribuição estatal: o Estado só pode tomar conhecimento da sua existência e prover a garantia do direito»: assim, A. Di Giovine, in G. Neppi Modonas (ed.), Stato della costituzione, Milano, 1995, sub art. 2, 10. Uma forma peculiar de jusnaturalismo se encontra em A. Baldassarre, Diritti inviolabili, cit., 11, segundo a qual os direitos em questão seriam não naturais, mas, todavia, "pré-estatais”, porque fundados sobre a vontade popular ou social, entendido o povo como entidade pré-estatal.

${ }^{18}$ P. Caretti, I diritti fondamentali. Libertà e diritti sociali, II ed., Torino, 2005, 136 s.; P. F. Grossi, I diritti di libertà ad uso di lezioni, cit., 95 ss., deduz do art. 1, alínea 2 («A soberania pertence ao povo, que a exerce nas formas e nos limites da Constituição»), a dupla tese de que «todo o nosso direito, nele compreendidas também as estatuições referentes à liberdade, encontra a sua fonte e extrai o seu fundamento na vontade popular e não em preceitos de um ordenamento natural», e que «os limites dessa soberania não podem ter outra base senão no sistema positivo» (p. 106). Nesse sentido, Grossi ecoa C. Esposito, La costituzione italiana. Saggi, Padova, 1954, 22 s.

${ }^{19}$ Recorde-se, por exemplo, o caso paradigmático da Déclaration des droits de l'homme et du citoyen, 1789 (que, a partir de seu nome, dá ares de texto simplesmente recognitivo de direitos naturais preexistentes): «Os homens nascem e permanecem livres e iguais nos direitos [...]» (art. 1); «O fim de toda associação política é a conservação dos direitos naturais e imprescritíveis do homem [...]» (art. 2). De "direitos naturais" se fala repetidamente na Constituição francesa de 1791 (título I). A Constituição francesa de 1848 estatui que a República «reconhece os direitos e os deveres anteriores e superiores às leis positivas » (preâmbulo, seção III).

${ }^{20}$ Cf., L. Mengoni, “Fondata sul lavoro”, cit., 4. Quanto às (não unívocas) ideologias dos constituintes italianos a esse respeito, pode-se ver A. Barbera, in G. Branca (ed), Commentario della costituzione. Principi fondamentali, Bologna-Roma, 1975, sub art. 2, 50 ss.; A. Baldassarre, "Diritti inviolabili", cit., 8 ss. Note-se que um argumento a favor da tese juspositivista poderia ser extraido dos trabalhos preparatórios da Constituição republicana: em particular, do fato de que formulações mais abertamente jusnaturalistas do art. 2 (ou, melhor, da disposição que depois viria a ser o art. 2) foram abandonadas. Penso, por exemplo, na fórmula proposta por Giorgio La Pira (na sessão de 9 de setembro de 1946): «direitos originários e imprescritíveis da pessoa humana».

${ }^{21}$ É um tanto peculiar a posição de L. Mengoni, “Fondata sul lavoro”, cit., 7, segundo o qual «A Constituição republicana repudiou o formalismo positivista e reconduziu o ordenamento jurídico a uma fundação última de ordem ética”.

DIREITOS FUNDAMENTAIS E J JUSTIÇA N 9 - OUT./DEZ. 2009 
importantes, concernentes: de um lado, a identificação dos direitos invioláveis; de outro, ao seu regime jurídico, com particular referência aos limites da revisão constitucional.

\section{QUAIS DIREITOS?}

Se se aceita a tese - um tanto discutível, como se viu - de que o art. 2 da Constituição, sem dúvida, reconheça ou atribua alguns direitos ditos "invioláveis", coloca-se obviamente o problema de identificá-los. Quais direitos são reconhecidos ou atribuídos por essa disposição e são, ao mesmo tempo, invioláveis? A resposta, evidentemente, não pode ser procurada no próprio art. 2, o qual não menciona concretamente nenhum direito subjetivo particular.

(1) Um jurista de orientação juspositivista responderá que - como não se dão, "in natura”, direitos subjetivos preexistentes ao ordenamento positivo - os direitos, a que se refere, com fórmula genérica, o art. 2 da Constituição, não podem ser senão aqueles expressamente enumerados e sumariamente disciplinados em outras disposições constitucionais ${ }^{22}$ : a liberdade pessoal (art. 13), a liberdade de domicílio (art. 14), a liberdade e sigilo de correspondência (art. 15), a liberdade de circulação e estadia (art. 16), e assim por diante. Desse ponto de vista, a fórmula do art. 2 faz, simplesmente, referência ao catálogo de direitos mencionados nas disposições constitucionais sucessivas ${ }^{23}$.

Além disso, de um ponto de vista juspositivista, o catálogo em questão é necessariamente uma lista fechada: na ausência de direitos "naturais” preexistentes à Constituição, outros direitos invioláveis, além daqueles expressamente enumerados pelo texto constitucional, não podem dar-se e não se dão ${ }^{24}$. Uma lista, portanto, não suscetível de integração por obra de algum poder constituído ${ }^{25}$ : entre outras coisas, pela boa razão de que todo "novo" direito, que se acrescentasse à lista mediante interpretação “criativa”, tenderia, fatalmente, a entrar em conflito com um ou com outro dos direitos preexistentes, textualmente acrescentados, e, por isso, a limitá-los ${ }^{26}$.

\footnotetext{
22 «Uma regra que tenha origem na ordem natural das coisas não pode ser considerada regra jurídica enquanto não tenha entrado no ordenamento jurídico vigente; e, pelo contrário, não pode ser considerada regra natural uma vez que se torne regra jurídica»: R. Carré de Malberg, Contribution à la théorie générale de l’État, Paris, 1920 (reimpressão Paris, 1962), vol. I, 239.

${ }^{23}$ P. Caretti, I diritti fondamentali, cit., 137 ss.

${ }^{24}$ Assim, por exemplo, P. Barile, Diritti dell'uomo e libertà fondamentali, Bologna, 1984, 54 ss.

${ }^{25}$ Em verdade, ninguém na doutrina entende estritamente "fechada" a lista dos direitos mencionados na Constituição. Todos entendem que a Constituição proteja seja os direitos que expressamente menciona, seja aqueles que são «deles consequentes» (P. Barile, Diritti dell'uomo e libertà fondamentali, cit., 56; cf., também, P. Barile, Libertà, giustizia, costituzione, Padova, 1993, 13 ss.). Algum bom exemplo se lê em A. Pace, Problematica delle libertà costituzionali, cit., 25 s., e em P. Caretti, I diritti fondamentali, cit., 140. Em outras palavras, também quem refuta a idéia, por excelência jusnaturalista, de uma lista aberta não sabe, pois, resistir à tentação de considerar o art. 2 da Constituição como "matriz" de uma série indeterminada de direitos ulteriores: falando de modo geral, pensa-se, com efeito, que sejam direitos invioláveis tanto os direitos "nominados”, quanto aqueles que deles decorrem como conseqüências pseudo-lógicas (cf., ainda, P. Barile, Diritti dell'uomo $e$ libertà fondamentali, cit., 56 ss.; C. Lavagna, Ricerche sul sistema normativo, Milano, 1984, 739 ss.; P. F. Grossi, Introduzione ad uno studio sui diritti inviolabili nella costituzione italiana, Padova, 1972, 169 ss.). ${ }^{26}$ A. Pace, Problematica delle libertà costituzionali, cit., 25 ss.; A. Pace, "Diritti "fondamentali” al di là della costituzione?”, in Politica del diritto, 1993, 4 s.; A. Pace, "Metodi interpretativi e costituzionalismo”,
} 
Aliás, quem se filia a este modo de ver deve responder a duas questões ulteriores entrelaçadas.

A primeira questão é se todos os direitos positivamente mencionados na Constituição devam ser considerados (em certo sentido, a determinar) "invioláveis”. O problema nasce do fato de que o adjetivo “inviolável” é empregado em outras disposições constitucionais que atribuem direitos - art. 13 (liberdade pessoal), art. 14 (liberdade de domicílio), art. 15 (liberdade e sigilo da correspondência), art. 24 (direito de defesa) - mas não em todos. Todos aqueles inclinados a uma interpretação fiel à letra do texto constitucional poderiam concluir que alguns direitos fundamentais são, sim, “invioláveis" - qualquer que seja o significado disso ${ }^{27}$ - nos sentidos da Constituição, mas outros direitos (as liberdades de reunião, de associação, de imprensa, etc.) não são, absolutamente, já que a Constituição não os qualifica como tais. Todavia, na doutrina, é tese pacífica - embora desprovida de argumentos textuais que todos os direitos civis $^{28}$ mencionados na Constituição sejam invioláveis ${ }^{29}$.

A segunda questão é se todos os direitos mencionados na Constituição devam ser considerados conferidos ao homem, como sugere a letra do art. 2 («...direitos invioláveis do homem»). O problema nasce de uma dupla circunstância. Em primeiro lugar, numerosos direitos subjetivos são expressamente atribuídos, pela Constituição, não ao homem, mas ao cidadão: por exemplo, o direito ao trabalho (art. 4), o direito de circulação e estadia (art. 16), o direito de reunião (art. 17), o direito de associação (art. 18), o próprio direito a igual tratamento (art. 3, alínea I). Em segundo lugar, o art. 10, alínea II, dispõe que a condição jurídica do estrangeiro seja regulada (não pela própria Constituição, ressalvadas as normas constitucionais expressamente referidas ao homem, e, portanto, também ao estrangeiro), mas «pela lei em conformidade com as normas [internacionais consuetudinárias] e com os tratados internacionais». Na doutrina, geralmente se entende que todos os direitos mencionados na Constituição são direitos do homem, e não só do cidadão ${ }^{30}$, mas este modo de ver, novamente, é desprovido de qualquer base textual.

in Quaderni costituzionali, 2001, 43 s. Cf., também, L. Paladin, Diritto costituzionale, cit., 568: “Toda vez que se abre e se alarga o catálogo dos direitos, é, de fato, inevitável que, em correspondência, se abra a série dos deveres e das obrigações”. Escreve M. Luciani, “Interpretazione costituzionale e testo della costituzione. Osservazioni liminari”, in G. Azzariti (ed.), Interpretazione costituzionale, Torino, 2007, 47: «se o intérprete, em particular o juiz, identificasse direitos "novos” [...], realizaria uma daquelas escolhas que [...] são reservadas ao poder constituinte. E o faria alterando o equilíbrio global dos direitos e - geralmente - dos valores constitucionais: nenhuma ampliação do catálogo dos direitos é sem custo, não só e nem tanto porque todo novo direito amplia as posições de desvantagem e sujeição que são funcionais a sua satisfação, mas também, e sobretudo, porque o novo direito altera a posição relativa dos direitos preexistentes, mudando os termos do balanceamento, ao qual estão destinados em caso de conflito com outros direitos ou valores concorrentes». ${ }^{27}$ Infra, § 4 .

${ }^{28}$ Diversos autores não entendem igualmente invioláveis alguns direitos "econômicos”, como o direito à iniciativa privada (art. 41) e à propriedade (art. 40). Esta tese é (persuasivamente) criticada por Pace, “Diritti ‘fondamentali’ al di là della costituzione?”, cit., 7 ss.

${ }^{29}$ Entende-se, a saber, que a expressa qualificação de invioláveis atribuída a alguns direitos, mas não a outros, seja «uma inútil redundância» (P. Barile, Diritti dell'uomo e libertà fondamentali, cit., 54). Assim, também, A. Di Giovine, in G. Neppi Modona (ed.), Stato della costituzione, cit., 11.

${ }^{30}$ Cf., por exemplo, M. Mazziotti di Celso, Lezioni di diritto costituzionale, Milano, 1985, vol. II, 56; L. Paladin, Diritto costituzionale, cit., 560. Diferente é a opinião de A. Pace, Problematica delle libertà costituzionali, cit. 
(2) Um jurista de orientação jusnaturalista responderá, pelo contrário, que o art. 2 da Constituição se refere a todos os direitos naturais (por isso mesmo, invioláveis) ${ }^{31}$.

Desse ponto de vista, a cláusula dos direitos invioláveis é, como dizem, uma cláusula "aberta" ${ }^{32}$ : não se refere somente aos direitos mencionados nas disposições constitucionais sucessivas ${ }^{33}$. Não se disse, com efeito, que a recognição dos direitos naturais realizada pelos constituintes tenha sido completa e exaustiva (pode dar-se que alguns direitos naturais tenham sido omitidos do catálogo).

Para aqueles que aderem, pois, à doutrina do direito natural variável, não está dito que novos direitos naturais, até aqui inexistentes, não possam nascer no curso do tempo da "natureza das coisas", da evolução da consciência social, ou algo do gênero $^{34}$. Este modo de ver, obviamente, legitima a integração do direito constitucional escrito mediante a elaboração, por parte dos intérpretes (e, particularmente, do juiz constitucional), dos direitos "naturais" não expressos ${ }^{35}$.

Por longo tempo, a Corte constitucional entendeu - com acurada atitude de self restraint - que o catálogo constitucional dos direitos fosse uma lista fechada. Leia-se, por exemplo, em uma decisão de 1980: “Os direitos fundamentais invioláveis, reconhecidos pelo art. 2 da Constituição, são aqueles relacionados às normas constitucionais específicas concernentes aos direitos e garantias individuais" ${ }^{36}$.

Ao mesmo tempo, porém, a Corte nunca excluiu que os direitos "nominados" na Constituição possam implicar em outros, “inominados”, se estes sejam condições necessárias de exercício daqueles “nominados” 37.

\footnotetext{
${ }^{31}$ A tese jusnaturalista não é muito difundida na doutrina. Mas a maioria da doutrina, mesmo sem fazer profissão de fé jusnaturalista, está inclinada à interpretação extensiva do art. 2. Cf., por exemplo, A. Barbera, in G. Branca (ed.), Commentario della costituzione. Principi fondamentali, cit., 65 ss., 102 ss.; A. Pizzorusso, Lezioni di diritto costituzionale, Roma, Il Foro Italiano, 1984, 87; P. Caretti, I diritti fondamentali, cit., 140. Diga-se, aliás, que não poucos juristas são jusnaturalistas sem sabê-lo: veja o caso de A. Baldassarre, "Diritti inviolabili", cit., 11 e 19, o qual, por um lado, nega que os direitos fundamentais sejam direitos “naturais”, mas, por um outro lado, afirma que eles são «estruturas necessárias (ontológicas do ser humano)».

${ }^{32}$ Assim se costuma dizer. A rigor, desse ponto de vista, o que é “aberto”, no sentido de incompleto, de não (necessariamente) exaustivo, é, antes, o catálogo de direitos mencionados nas sucessivas disposições constitucionais.

${ }^{33}$ Segundo A. Pizzorusso, Lezioni di diritto costituzionale, cit., 87, a norma é «aberta a todas aquelas interpretações que resultem consentidas pelos textos normativos à luz do sentimento de justiça e da consciência social dos cidadãos».

${ }^{34}$ Assim, por exemplo, segundo A. Barbera, in G. Branca (ed.), Commentario della costituzione. Principi fondamentali, cit., 84 s., novos direitos podem surgir em conformidade «aos valores e aos interesses novos que vão emergindo por obra das forças políticas e culturais prevalentes, das forças políticas, isto é, que determinam a Constituição material». Desse ponto de vista, pode-se bem dizer que a cláusula do art. 2 seja “aberta” em sentido estrito, ou seja, não concluída. Cf., por exemplo, C. Mortati, Istituzioni di diritto pubblico, cit., vol. I, 146; G. Zagrebelsky, Il diritto mite, Torino, Einaudi, 1992, 70; A. Baldassarre, "Diritti inviolabili”, cit. ${ }^{35}$ Sobre a "positivação” de "novos” direitos fundamentais, cf., A. Ruggeri, “'Nuovi’ diritti fondamentali e tecniche di positivizzazione”, in Studi in onore di Manlio Mazziotti di Celso, Padova, 1995, vol. II, spec. 628 ss.

${ }^{36}$ Corte constitucional 188/1980. Todavia, em uma sentença precedente a Corte havia incluído entre os direitos invioláveis também a "situação jurídica do concebido", de quem não se encontra traço na Constituição (Corte constitucional 27/1975).

${ }^{37}$ Corte constitucional 98/1979. Em uma decisão, por exemplo, a Corte entendeu que a renúncia a usufruir uma anistia constitua «explicação do direito de defesa», garantido pelo art. 24, alínea 2, da Constituição. (Corte constitucional 175/1971). A Corte entendeu, também, que o «direito à informação [seja] pressuposto
} 
Como quer que seja, a partir dos anos oitenta do século passado ${ }^{38}$, a jurisprudência da Corte conheceu uma significativa evolução. A fórmula do art. 2 da Constituição entende agora a Corte - é "fechada” respectivamente aos valores estranhos aqueles encontrados na Constituição, mas "aberta” às novas manifestações que estes valores assumem em contextos sociais mudados. De fato, na jurisprudência constitucional dos últimos vinte anos se encontram, assim reconhecidos, certos direitos fundamentais invioláveis, entre outros ${ }^{39}$ : a liberdade sexual ${ }^{40}$, o direito social à habitação ${ }^{41}$, o direito à honra e à reputação ${ }^{42}$, o direito à instrução ${ }^{43}$, o direito à privacidade e a uma comunicação livre e secreta ${ }^{44}$, o direito a abandonar o próprio país ${ }^{45}$, o direito à identidade pessoal ${ }^{46}$. Direitos, todos, os quais não se encontra traço no texto constitucional ${ }^{47}$.

\section{4. “INVIOLÁVEIS”: EM QUE SENTIDO?}

Posto que todos ou alguns dos direitos proclamados na Constituição são "invioláveis", é preciso obviamente questionar-se em que sentido são assim. A qualificação de certos direitos como “invioláveis” é uma mera fórmula declamatória - característica da linguagem retórica comumente empregada pelos redatores dos textos constitucionais ${ }^{48}$ - e como tal, desprovida de qualquer conteúdo normativo preciso, ou, pelo contrário, é cheia de efeitos jurídicos ${ }^{49}$ ? Também a solução desse problema está fatalmente condicionada pelas opções filosófico-jurídicas dos intérpretes ${ }^{50}$.

(1) Os partidários do jusnaturalismo entendem que a qualificação de inviolabilidade exprime uma vedação de revisão constitucional ${ }^{51}$. Se os direitos constitucionais já não foram criados ex novo, mas simplesmente declarados pelos constituintes, então os direitos em questão não podem ser suprimidos de modo algum, nem sequer mediante revisão constitucional: como são dados in natura - pois nenhuma autoridade

da liberdade de manifestação do pensamento» (Corte Constitucional 1/1981); que «a autonomia contratual dos indivíduos» seja «instrumento de exercício de liberdades constitucionais garantidas», e, mais precisamente, «meio de explicação da liberdade de iniciativa econômica» (Corte Constitucional 268/1994); etc.

38 Precisamente, a partir da sentença 561/1987. Ver, a propósito, A. Pace, "Metodi interpretativi e costituzionalismo", cit., $50 \mathrm{~s}$.

${ }^{39}$ A lista, que segue, é incompleta. Veja-se uma lista mais ampla em E. Rossi, in R. Bifulco, A. Celotto, M. Olivetti (ed.), Commentario alla Costituzione, cit., $46 \mathrm{s.}$

${ }^{40}$ Corte Constitucional 561/1987.

${ }^{41}$ Corte Constitucional 217/1988, 404/1988, 419/1991.

${ }^{42}$ Corte Constitucional 1150/1988.

${ }^{43}$ Corte Constitucional 215/1987.

${ }^{44}$ Corte Constitucional 366/1991, 81/1993.

${ }^{45}$ Corte Constitucional 278/1992.

${ }^{46}$ Corte Constitucional 13/1994.

47 Assim dizendo, não se quer criticar a jurisprudência constitucional, mas só descrevê-la de modo a esclarecer o componente nomopoietico.

${ }^{48}$ Em outros textos constitucionais os direitos fundamentais são qualificados “inalienáveis”, "imprescritíveis”, “eternos”, “sagrados”, “originais”, “inatos”, etc.

${ }^{49}$ Só neste segundo caso se poderia dizer que o art. 2 da Constituição não se limita a mencionar os direitos invioláveis, mas, assim fazendo, dita (Corte Constitucional), também, uma certa disciplina.

${ }^{50}$ As diferentes acepções possíveis do vocábulo "invioláveis" são analisadas por L, Mengoni, "Fondata sul lavoro", cit., 4 s.

${ }^{51}$ Ver, por exemplo, W. Sabète, Pouvoir de révision constitutionnelle et droits fondamentaux, Rennes, Presses universitaires de Rennes, 2005. 
normativa humana os criou - com maior razão, nenhuma autoridade humana os pode suprimir. Em suma: “inviolável” significa absolutamente "intangível”52, e, portanto, não suscetível de revisão constitucional ${ }^{53}$.

Diga-se que na doutrina constitucionalista italiana esta opinião é quase pacífica. Todavia, raramente ela é argumentada (como, todavia, seria de se esperar) com posições jusnaturalistas ${ }^{54}$. Um (fraco) argumento recorrente é, pelo contrário, aquele segundo o qual os direitos em questão são “coessenciais”, respectivamente à forma de Estado (democrática) instaurada pela Constituição ${ }^{55}$.

(2) Os partidários do juspositivismo, pelo contrário, entendem que a qualificação de inviolabilidade: se contida em uma Constituição flexível, seja uma mera fórmula declamatória, desprovida de efeitos jurídicos; se contida em uma Constituição rígida, como a Constituição italiana vigente, não acrescenta nada à rigidez das normas constitucionais que conferem direitos (rigidez que descende, obviamente, já não do art. 2, mas das normas sobre a revisão constitucional) ${ }^{56}$.

Em outras palavras, os direitos constitucionais são certamente invioláveis para o legislador (ordinário) ${ }^{57}$, e, de modo geral, para os poderes públicos, como qualquer outra norma, de resto, constitucional. Mas as normas constitucionais que conferem direitos podem, tranquilamente, como qualquer outra norma, ser ab-rogadas, derrogadas, ou substituídas - entenda-se, com os procedimentos apropriados (neste caso, com o procedimento de revisão constitucional) - quando isso não seja expressamente vedado por alguma norma positiva. De outra parte, a Constituição vigente veda somente a revisão da forma republicana do Estado (art. 139); de modo que a vedação de revisão pode dizer respeito, no máximo, a todos e só aqueles direitos subjetivos que se entendem definidores da forma republicana, aqueles, isto é, na ausência dos quais a forma do Estado, por definição, não seria mais "republicana"58.

52 Intangível «por obra de qualquer poder público, seja como for explicado»: assim, L. Paladin, Diritto costituzionale, cit., 559. Cf., também, C. Mortati, Dottrine generali e costituzione della Repubblica italiana, Milano, 1986 (extraído da Enciclopedia del diritto, vol. XI, Milano, 1962), 206; P. F. Grossi, Introduzione ad uno studio sui diritti inviolabili nella costituzione italiana, cit., 94 ss.; A. Pizzorusso, Lezioni di diritto costituzionale, cit., 520; A. Di Giovine, in G. Neppi Modona (ed.), Stato della costituzione, cit., 11.

${ }^{53}$ Cf., por exemplo, P. Barile, Diritti dell'uomo e libertà fondamentali, cit., 47, 53 s.; T. Martines, Introduzione al diritto costituzionale, Torino, 1994, 34 ss.; P. Caretti, I diritti fondamentali, cit., 141 ss.

${ }^{54}$ Uma doutrina francamente jusnaturalista seria o modo mais óbvio de dar fundamento à tese de que exista uma norma jurídica (em particular: uma vedação de revisão constitucional) desprovida de qualquer correspondência textual no direito positivo.

${ }^{55}$ L. Paladin, Diritto costituzionale, cit., 565. Este modo de ver parece supor uma concepção "substancialista" da Constituição e da revisão constitucional (dir-se-á algo a frente). Cf., a propósito, R. Guastini, Lezioni di teoria del diritto e dello stato, Torino, 2006, 15 ss.

${ }^{56}$ A. Pace, Problematica delle libertà costituzionali, cit., 41 ss.; S. Cicconetti, La revisione della costituzione, Padova, 1972, 273 ss.; S. Cicconetti, Appunti di diritto costituzionale, II ed., Torino, 1992, 103 ss. Um possível contra-argumento é o seguinte: se a disposição que qualifica certos direitos como invioláveis não tivesse outro sentido senão aquele de proibir a violação por parte do legislador ordinário, então tal disposição seria redundante respectivamente àquela que torna rígida a Constituição, prescrevendo um procedimento agravado de revisão constitucional. Cf., por exemplo, E. Rossi, in R. Bifulco, A. Celotto, M. Olivetti (ed.), Commentario alla Costituzione, cit., 44.

${ }^{57}$ A. Pace, La libertà di riunione nella costituzione italiana, Milano, 1967, $155 \mathrm{~s}$.

${ }^{58}$ A. Pace, Problematica delle libertà costituzionali, cit., 45. Esse modo de ver pressupõe que alguns direitos 
De fato, a doutrina que identifica a inviolabilidade com a vedação de revisão constitucional foi feita, exatamente - sem nenhuma argumentação - pela Corte Constitucional $^{59}$.

Entende a Corte que a Constituição vigente inclua não só limites expressos (a forma republicana: art. 139), mas também limites não expressos à revisão constitucional: seria, portanto, constitucionalmente ilegítima uma lei de revisão constitucional que pretendesse transpô-los. A Corte entende, igualmente, que tais limites tenham caráter absoluto, no sentido de que não podem ser afastados por algum modo legítimo.

São limites não expressos à revisão - segundo a Corte - os «princípios supremos» ou «valores supremos», sobre os quais a Constituição vigente «se funda». São, igualmente, limites não expressos à revisão os «direitos inalienáveis da pessoa humana» ${ }^{60}$.

Essa orientação jurisprudencial parece supor, mais ou menos, o seguinte raciocínio. (a) É necessário distinguir entre a revisão da Constituição existente e a instauração de uma nova Constituição. (b) Por definição, o poder de revisão, como poder constituído, não pode ser compelido até instaurar uma nova Constituição. (c) A revisão, diferentemente da instauração, supõe que a Constituição existente conserve a sua identidade. (d) A Constituição, porém - note-se bem - não é um simples conjunto de normas: é uma totalidade coesa de princípios e valores; em suma, a sua identidade reside, precisamente, no conjunto destes princípios e valores. (e) Conseqüentemente, uma revisão que tocasse nos princípios supremos não seria uma genuína revisão: do ponto de vista substancial, seria uma instauração constitucional camuflada nas formas da revisão. (f) Portanto, a revisão dos princípios e valores que caracterizam a Constituição é vedada ${ }^{61}$.

subjetivos - como o direito a igual tratamento, à liberdade de manifestação e propaganda, de reunião e de associação, o direito de voto e de acesso aos serviços públicos (assim, A. Pace) - sejam definidores do próprio conceito de república, de modo que, por definição, um Estado não é uma república na ausência desses direitos. Que também a Espanha e o Reino Unido sejam repúblicas... sem sabê-lo? Aliás, os direitos fundamentais não se encontram na lista dos princípios entendidos "coessenciais” da forma republicana redigida, por exemplo, por G. Volpe, in G. Branca (ed.), Commentario della costituzione. Garanzie costituzionali, Bologna-Roma, 1981, sub art. 139, 744 s.

${ }^{59}$ Corte Constitucional 1146/1988. Cf., também, Corte Constitucional 366/1991: «com base no art. 2, o direito a uma comunicação livre e secreta é inviolável, no sentido geral de que o seu conteúdo essencial não pode ser objeto de revisão constitucional, enquanto incorpora um valor da personalidade, possuindo um caráter fundante, respectivamente ao sistema democrático quisto pelo constituinte».

${ }^{60}$ Corte Constitucional 1146/1988. Assim dizendo, a Corte assume, evidentemente, que os princípios, valores, e direitos em questão, tenham "uma valência superior", respectivamente à própria Constituição e, com maior razão, respectivamente às leis de revisão constitucional: esses são, em suma, axiologicamente superiores às demais normas de nível constitucional. Leia-se o que escrevia a Corte em uma decisão agora retomada: «é de compartilhar o assunto da subsistência de uma hierarquia entre normas e normas da própria Constituição, respectivamente à qual é individuável (como, de resto, em todo corpo de disposições ordenadas em sistema) uma ordem que conduz a conferir preeminência a algumas dessas, em relação a outras» (Corte Constitucional., 175/1971). Sobre o conceito de hierarquia axiológica, cf., R. Guastini, Lezioni di teoria del diritto e dello stato, cit., cap. II.

${ }^{61}$ É essa, a grosso modo, a doutrina de C. Mortati, Dottrine generali e costituzione della Repubblica italiana, cit., 208 ss. Encontram-se traços também em P. Caretti, I diritti fondamentali, cit., 144, e naqueles que, como ele, concebam a Constituição não como um mero conjunto de normas, mas como a transcrição de um "pacto social".

DiReITOS FundaMentals $\varepsilon$ E JUSTIÇA N 9 - OUt./DEZ. 2009 
Trata-se de uma concepção “substancialista” da Constituição e da revisão constitucional que não é, por nada, óbvia. A ela é fácil rebater que: (i) a Constituição é só um conjunto de normas, definível extensivamente por simples enumeração das normas que a compõem ${ }^{62}$; (ii) a superioridade axiológica de algumas normas (os princípios supremos, os direitos inalienáveis) às outras é fruto de um juízo de valor subjetivo, desprovido de qualquer fundamento jurídico positivo; (iii) a revisão constitucional se distingue da instauração de uma nova Constituição sob o aspecto formal (a revisão constitucional se realiza por formas legais, a instauração constitucional se realiza por formas ilegais, extra ordinem); (iv) a Constituição existente conserva a sua identidade até que não seja substituída por formas ilegais ${ }^{63}$.

\section{SEM CONCLUSÃO}

Este ensaio é programaticamente desprovido de conclusões. Propus-me simplesmente a mostrar - com atitude moderadamente detached ${ }^{64}$ - alguns problemas interpretativos levantados por uma determinada cláusula constitucional em matéria de direitos fundamentais. Todavia, não sei renunciar a fazer uma pequena observação final em tema de teoria da interpretação.

A teoria da interpretação hoje dominante - propiciada pela obra de Herbert Hart $^{65}$ - sustenta que (salvo, talvez, qualquer caso esporádico de ambigüidade dos enunciados normativos) os problemas interpretativos são, todos e somente, do tipo seguinte. Dado, por exemplo, um enunciado normativo que prescreve "É proibido o ingresso dos veículos no estacionamento”, pergunta-se-nos se a norma se estenda às bicicletas, aos patins, ao carro dos bombeiros ou da polícia, ao caminhão que transporta uma estátua para ser instalada no próprio estacionamento, e similares.

Em outras palavras, os problemas interpretativos seriam essencialmente:

(a) problemas de referência ou extensão dos predicados (predicados em sentido lógico: termos que denotam classes);

(b) problemas dependentes da intrínseca imprecisão, open texture, dos próprios predicados;

\footnotetext{
${ }^{62}$ E. Bulygin, “Time and Validity”, in A. A. Martino (ed.), Deontic Logic, Computational Linguistics and Legal Information Systems, Amsterdam, North Holland, 1982; R. Guastini, L'interpretazione dei documenti normativi, Milano, 319 ss.

${ }^{63}$ Poder-se-ia acrescentar uma objeção ulterior. A não revisão dos princípios supremos e dos direitos inalienáveis constitui, ao que parece, um limite "lógico” à revisão constitucional: ou seja, um limite derivado não do direito positivo, mas “da lógica”, isto é, concretamente do modo pelo qual são estruturados os conceitos (no nosso caso, os conceitos de Constituição e de revisão constitucional). Mas a própria idéia de um limite lógico à revisão constitucional é desprovida de sentido. A revisão constitucional, como qualquer outro ato jurídico, pode estar sujeita só a limites jurídicos, não lógicos. Mas, de outra parte, um limite jurídico não pode decorrer senão de uma norma jurídica positiva.

${ }^{64}$ Moderadamente imparcial: de fato, não soube resistir à tentação de sugerir que algumas opções interpretativas parecem mais sólidas (e mais persuasivamente argumentáveis), ao menos para aqueles que prestam respeito ao texto constitucional.

${ }^{65}$ H. L. A. Hart, The Concept of Law, Oxford, 1961, cap. VII. Cfr. G. R. Carrió, Notas sobre derecho y lenguaje, IV ed., Buenos Aires, 1994, spec. 49 ss.; E. Bulygin, "Sull'interpretazione giuridica”, in P. Comanducci, R. Guastini (a cura di), Analisi e diritto 1992. Ricerche di giurisprudenza analitica, Torino, 1992; J. J. Moreso, La indeterminación del Derecho y la interpretación del la Constitución, Madrid, 1997, spec. 218 ss.
} 
(c) imprecisão que não é peculiar à linguagem jurídica, mas - segundo o ensinamento de Friedrich Waismann ${ }^{66}$ - comum a todo tipo de linguagem não formalizada.

Pois bem, é suficiente estudar de perto um certo problema sério de interpretação, efetivamente discutido pela doutrina e pela jurisprudência, para se dar conta de quanto é ingênuo este modo de ver. Os problemas de referência (Bedeutung) dos predicados concernem ao campo de aplicação das normas: são problemas de subsunção de fattispecie concretas sob fattispecie abstratas previamente identificadas. Mas os problemas primários ${ }^{67}$ de interpretação não são inteiramente deste tipo: eles dizem respeito, antes, à identificação da própria fattispecie abstrata, isto é, o sentido (Sinn) do enunciado interpretado: enfim, a norma (ou as normas) que esse exprime (e/ou implica).

Aparentemente, a (culpada) ingenuidade da teoria dominante depende da assimilação - por vezes tácita, mas freqüentemente explícita - entre linguagem jurídica e linguagem ordinária. E isso, por sua vez, depende, pelo quanto possa surpreender (já que a teoria em questão é sustentada também por juristas competentes), da simples ignorância da prática jurídica.

A comunicação especificamente jurídica - o “diálogo” entre as autoridades normativas e os intérpretes - é diferente da comunicação ordinária, e, talvez, de qualquer outro tipo de comunicação. A interpretação dos textos normativos é condicionada não só por interesses práticos conflitantes, o que deveria ser óbvio, mas - freqüentemente - por posições filosófico-jurídicas e/ou filosófico-políticas e sempre - por construções dogmáticas elaboradas, que são, de todo, estranhas à conversação quotidiana ${ }^{68}$. Não existe uma “dogmática” da conversação quotidiana. Os juristas são capazes de tornar equivoco qualquer enunciado, cuja interpretação seria de todo pacífica em contextos não jurídicos.

${ }^{66}$ F. Waismann, “Verifiability”, in F. Waismann, How I See Philosophy, London, MacMillan, 1968.

${ }^{67}$ Primários em sentido tanto lógico, quanto axiológico: ou seja, logicamente prévios e ao mesmo tempo mais importantes.

${ }^{68}$ É um dos ensinamentos de G. Tarello: cf., por exemplo, Diritto, enunciati, usi, Bologna, 1974, spec. 329 ss. 